\title{
Concurrent use of the Pipeline Embolization Device and coils for intracranial aneurysms: technique, safety, and efficacy
}

\author{
Erez Nossek, MD, ${ }^{1}$ David J. Chalif, MD, ${ }^{1}$ Shamik Chakraborty, MD, ${ }^{1}$ Kim Lombardo, RN, NP, ${ }^{2}$ \\ Karen S. Black, MD, ${ }^{2}$ and Avi Setton, MD ${ }^{1,2}$
}

Departments of ${ }^{1}$ Neurosurgery and ${ }^{2}$ Radiology, Hofstra North Shore-Long Island Jewish School of Medicine, and North ShoreLong Island Jewish Health System, Manhasset, New York

\begin{abstract}
OBJECT The use of the Pipeline Embolization Device (PED) as a sole endovascular modality has been described for the treatment of brain aneurysms. The benefit of using coils concurrently with a limited number of PEDs is not well documented. The authors describe their experience with this technique as well as their midterm clinical and angiographic results.
\end{abstract}

METHODS This is a retrospective review of patients treated between 2011 and 2014. The authors placed a minimal number of PEDs with the addition of coils using a "jailed" microcatheter technique. A partially dense coil mass was obtained. Immediate and midterm clinical and angiographic results are reviewed.

RESULTS The authors treated 27 patients harboring 28 aneurysms using this technique. The mean aneurysm size was $11.9 \mathrm{~mm}$, and the mean neck size was $5.4 \mathrm{~mm}$. A mean of 1.48 PEDs were placed per patient, and a mean of 1.33 PEDs per aneurysm were placed. The Raymond score immediately after PED placement was 2 or 3 in $82.1 \%$ of the patients.

There were no intraprocedural or postprocedural complications. All PEDs were successfully deployed. No clinical or technical adverse effects related to the coil mass were observed. There were no clinical or radiographic signs of ischemia in this group. At follow-up imaging, complete aneurysm occlusion was demonstrated on the first MR angiogram (3-5 months) in all patients who reached this milestone. Follow-up digital subtraction angiography (5-13 months) confirmed complete occlusion in all patients who reached this milestone. All patients maintained their baseline clinical status.

CONCLUSIONS The deployment of PEDs with concurrent partially dense coiling is safe and efficacious. This technique achieved early complete occlusion and endovascular reconstruction of the parent vessel, without inducing mass effect. Favorable midterm clinical results were observed in all patients.

http://thejns.org/doi/abs/10.3171/2014.12.JNS141259

KEY WORDS aneurysm; brain; coil; Pipeline Embolization Device; vascular disorders

$\mathrm{F}$ LOW-DIVERTER devices were originally reported to modify and redirect flow as a treatment option for wide-neck aneurysms. ${ }^{1,2,10,14-16,26}$ The Pipeline Embolization Device (PED; ev3 Neurovascular) has been approved specifically to treat large, wide-neck proximal internal carotid artery (ICA) aneurysms at the cavernous ICA and ophthalmic artery segments as a sole device. ${ }^{1,16}$ There are few published descriptions of the concurrent use of PEDs and coils. ${ }^{8,21,24} \mathrm{~A}$ detailed and specific description of this technique, as well as its benefits and limitations has not as yet been presented in the current literature.
In a multicenter study of the use of PEDs for aneurysms that cannot be treated with coils or aneurysms for which treatment has failed (the Pipeline for Uncoilable or Failed Aneurysms study), where PEDs were used as a sole endovascular device (without concurrent coiling), the mean number of PEDs used was 3, and $98.1 \%$ of the patients received more than 1 PED. ${ }^{1}$ In another large series of patients treated using PEDs as the sole device, the mean number of PEDs per patient was 1.7. ${ }^{21}$ Our treatment paradigm focused on the reduction in the number of PEDs used per aneurysm, while simultaneously achieving rapid and com-

ABBREVIATIONS ICA = internal carotid artery; MRA = MR angiography; $m R S=$ modified Rankin Scale; PED = Pipeline Embolization Device; PRU = P2Y12 reaction units SUBMITTED June 6, 2014. ACCEPTED December 15, 2014.

INCLUDE WHEN CITING Published online February 6, 2015; DOI: 10.3171/2014.12.JNS141259.

DISCLOSURE The authors report no conflict of interest concerning the materials or methods used in this study or the findings specified in this paper. 
plete aneurysm obliteration with the simultaneous addition of a partially dense coil mass. We have analyzed this technique in respect to aneurysm occlusion rates, timing of occlusion, and procedural complications. We have also reviewed and quantified immediate results and midterm clinical and angiographic outcomes.

\section{Methods}

This is a retrospective analysis of patients who were treated for intracranial aneurysms between 2011 and 2014 at our institution. Intuitional review board approval was received. In this cohort, we aimed to treat the aneurysm with a single PED across the aneurysm neck. In cases in which a second PED was used, most were deployed to achieve proximal anchoring of the first PED due to lack of proper wall apposition as a result of the caliber difference between the parent vessel at the aneurysm neck and at the proximal landing zone. Subsequent to PED placement, we proceeded to embolize the aneurysm with a partially dense coil mass after "jailing" a microcatheter in the aneurysmal sac.

\section{Preoperative Protocol}

All patients were started on dual antiplatelet therapy that included $75 \mathrm{mg}$ clopidogrel and $81 \mathrm{mg}$ aspirin between 5 and 7 days prior to the procedure. A P2Y12 assay (VerifyNow, Accumetrics) was obtained in all patients 1 day prior to the procedure to evaluate and confirm the level of platelet inhibition obtained by the dual antiplatelet regimen. Treatment was performed only after confirmation of response to these agents $(<180$ P2Y12 reaction units [PRU]). Patients who demonstrated higher levels of PRU were treated with $150 \mathrm{mg}$ clopidogrel, and a second PRU level was obtained on the day of the procedure. Patients who did not respond to clopidogrel were treated with Effient (10 mg), and were then reevaluated by PRU assays. Treatment for hyporesponsive patients was cancelled and rescheduled after an appropriate and acceptable response to the antiplatelet treatment was determined. In cases in which we recognized a hyperresponding assay, we continued with the procedure as scheduled.

Four-vessel diagnostic angiography was performed in all patients, and 3D reconstructed images were created. In cases in which we planned to extend the PED into the $\mathrm{M}_{1}$ segment with covering of the $\mathrm{A}_{1}$ segment origin, ${ }^{17}$ a thorough bilateral angiographic assessment of flow dynamics in the anterior circle of Willis was performed.

\section{Interventional Procedure}

All embolization procedures were performed via a standard transfemoral approach under full heparinization. The specific dimensions of the PED were chosen for each case after quantitation of the size of the aneurysmal neck and parent vessel diameter at the level of the aneurysmal neck and at the level of the landing zones. We attempted to match the size of the nominal PED diameter relative to the proximal landing zone and to the diameter of the parent vessel at the aneurysmal neck to maximize flow diversion. ${ }^{22}$

An 8-F sheath was used. We used a triaxial system with an 8-F guiding catheter, an intermediate catheter (DAC $0.44 / 115$, Stryker Neurovascular) and the Marksman microcatheter (ev3 Neurovascular) to deliver the PED. After positioning the microcatheter distal to the aneurysmal neck, we navigated a second microcatheter, parallel to the DAC, into the aneurysm sac to subsequently deploy coils via this "jailed" microcatheter. After deployment of the PED we continued with coil embolization, with the objective to achieve only a partially dense coil mass within the aneurysmal sac, without maximal packing and without total occlusion of the neck bridged by the PED (Figs. 1-3). We used the Raymond classification system ${ }^{20}$ to assess the angiographic immediate post embolization result.

\section{Postprocedural Management and Follow-Up}

We used short-term (4-5 days) low-dose steroid treatment in the periprocedural period. Clopidogrel was discontinued soon after MR angiography (MRA) demonstrated complete occlusion (4-5 months).

We used a strict clinical and imaging follow-up protocol for the patients in our cohort. Follow-up imaging was performed using MRA in a high-field magnet, with and without contrast, at 3 months postembolization to assess aneurysm occlusion. ${ }^{7,28,30}$ Review of source images, without and with contrast, was performed to assess ischemic territories or increased mass effect when clinical symptoms were absent. These images were compared with baseline studies. Formal cerebral angiography was also performed 6-12 months after the procedure. We used the Raymond classification to assess the angiographic results and compared them with the immediate postprocedural results. We elected to grade the occlusion grade in the immediate postembolization and midterm follow-up studies using the Raymond classification system and not the O'Kelly classification system, ${ }^{19}$ as we relied not only on flow diversion for aneurysmal occlusion, but on the combination of flow diversion augmented with coils. Two independent neuroradiologists evaluated follow-up images.

Immediate (3-5 months postprocedure) and midterm (9-12 months postprocedure) clinical examinations and assessments were also reviewed, utilizing the modified Rankin Scale. All patients with proximal carotid aneurysms underwent pre- and postprocedure (at 4-6 weeks) formal neuroophthalmological evaluations.

\section{Results}

\section{Patient Demographics and Aneurysm Characteristics}

Twenty-seven patients with 28 aneurysms were included in the current study and were treated between 2011 and 2014 with the combination of PEDs and concurrent use of coils. There were 26 female patients in the cohort. The median age was 51 years (range $31-78$ years) (Table 1 ). The aneurysms sites are documented in Table 2 . Two patients $(7.4 \%)$ presented with subarachnoid hemorrhage and were treated with partial coiling in the acute phase. A PED was then deployed in the subacute phase (one at 3 weeks and the other at 3 months after the rupture) in these 2 patients to achieve complete occlusion. Twenty-five patients with unruptured aneurysms presented with normal findings on neurological examination (modified Rankin 

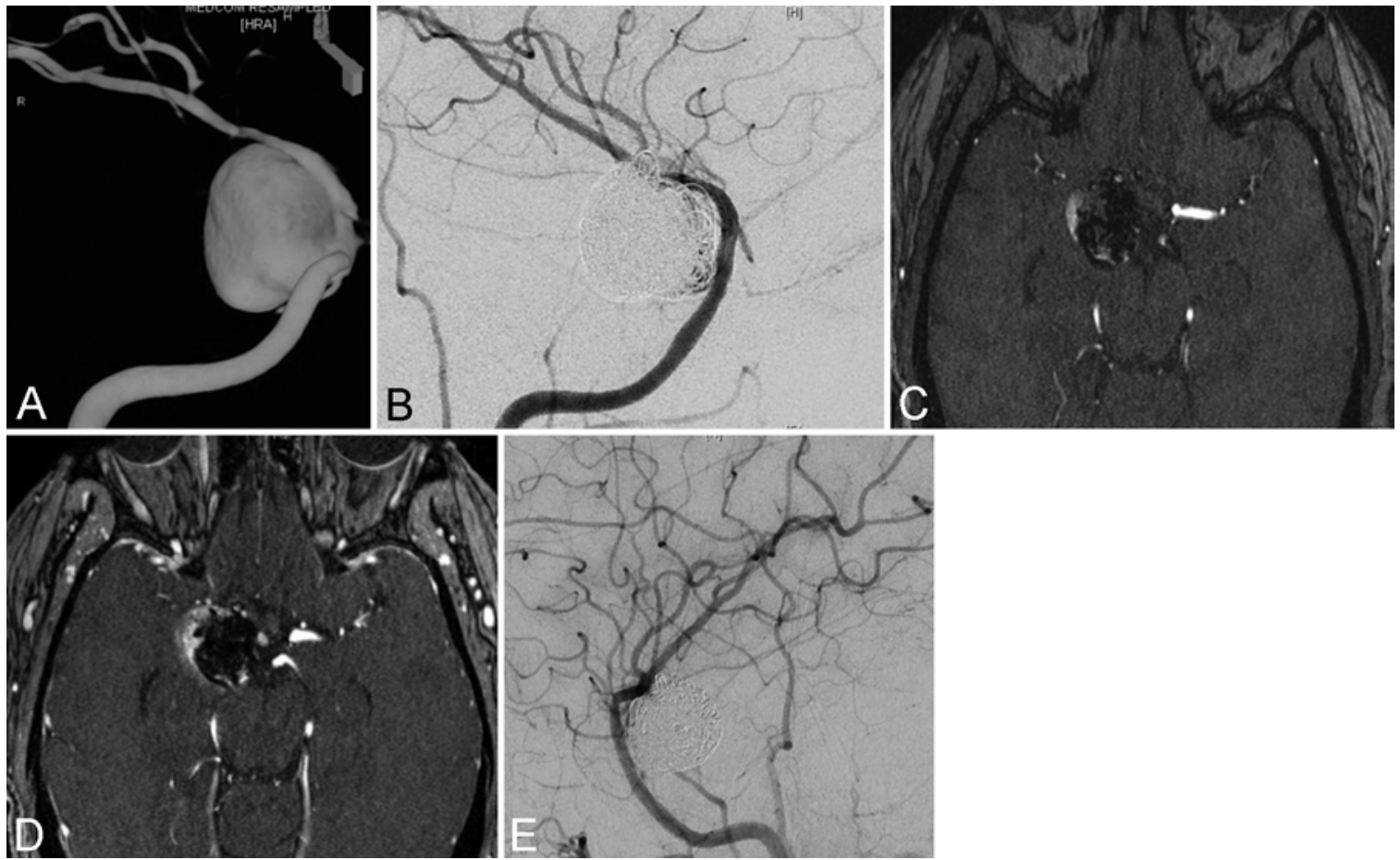

FIG. 1. A: Three-dimensional angiographic reconstruction of a giant posterior communicating artery aneurysm. B: Postembolization injection after deployment of a single PED and concurrent embolization with a partially dense coil mass. Note residual contrast stagnation in the aneurysm sac. C and D: Follow-up MR angiograms obtained 3 months postprocedure with $(C)$ and without (D) contrast, demonstrating complete occlusion of the aneurysm. Note hyperintense peripheral signal in the noncontrast study compatible with thrombosis. This area does not enhance after contrast administration. In addition, linear peripheral enhancement compatible with target sign is demonstrated. E: Follow-up angiogram obtained 12 months after the procedure, demonstrating complete occlusion of the aneurysm, without in-stent stenosis. The reverse oblique view is shown in order to demonstrate complete endovascular reconstruction of the ICA with complete obliteration of the neck.

Scale [mRS] Score 0). The 2 patients with previously ruptured aneurysms recovered completely and presented with normal neurological function (mRS Score 0 ) at the time of the stent procedure.

The mean maximal aneurysm sac diameter was 11.9 $\mathrm{mm}$ (median $10.3 \mathrm{~mm}$, range $4.2-31 \mathrm{~mm}$ ). The mean neck size was $5.4 \mathrm{~mm}$ (median $5 \mathrm{~mm}$, range 3-14 mm), with $22(78.6 \%)$ wide-neck aneurysms ( $\geq 4 \mathrm{~mm}$ or dome/neck ratio $\leq 2)$. There were 13 small aneurysms $(<10 \mathrm{~mm}), 13$ large aneurysms (10-24 mm; in this group 3 were larger than $15 \mathrm{~mm}$ ) and 2 giant aneurysms (>25 mm) (Fig. 1). Of note, in this cohort, small aneurysms were treated with the PED as an off-label device.

\section{Procedural and Postprocedural Results}

In our cohort, 1-3 PEDs (mean 1.33) were deployed across aneurysm necks (19 patients [70.4\%] were treated with a single PED across the neck). Overall, 17 patients (63\%) received a single PED, 7 patients (25.9\%) received 2 PEDs, and 3 patients $(11.1 \%)$ received 3 PEDs.

Ten patients received more than 1 PED. Three patients underwent placement of another PED (which did not cross the aneurysm neck) to achieve better anchoring of the first PED in light of caliber differences between the cavernous ICA and supraclinoid ICA. In 7 patients, a second PED was intentionally deployed across aneurysm necks; in 6 patients the neck was excessively wide (mean neck size 7.5
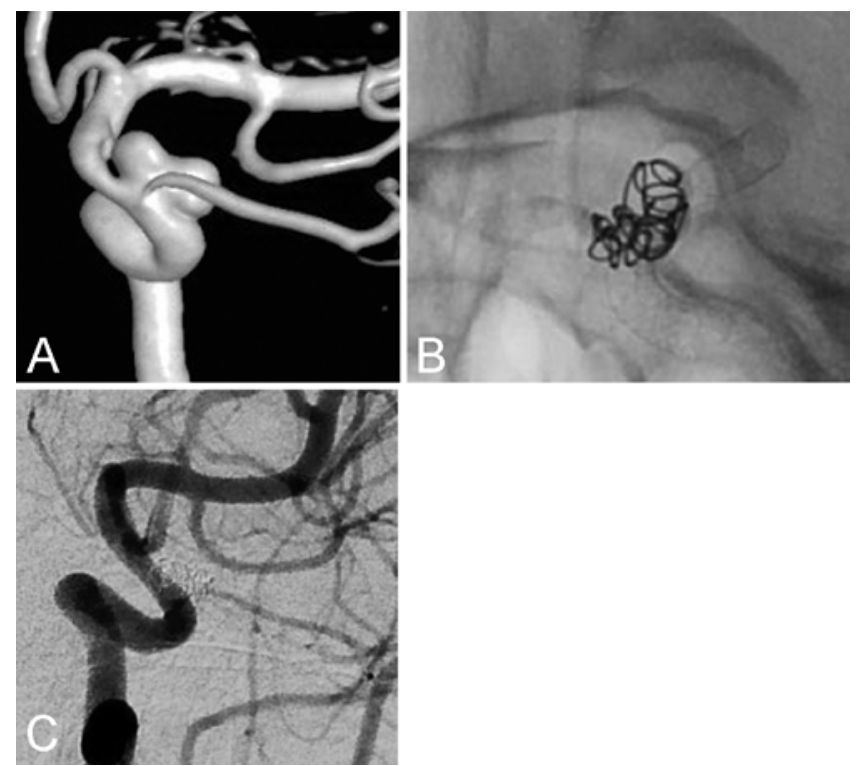

FIG. 2. A: Three-dimensional angiographic reconstruction of an ophthalmic artery wide-neck aneurysm with a shallow aneurysmal fundus. Note the narrowing of the parent vessel at the level of the distal aneurysmal neck. B: Plain radiograph demonstrating a single PED in the parent vessel and partially dense coil mass. C: Follow-up angiogram obtained 8 months after the procedure, demonstrating complete occlusion of the aneurysm, without in-stent stenosis. Note complete endovascular reconstruction and remodeling of the ICA. 


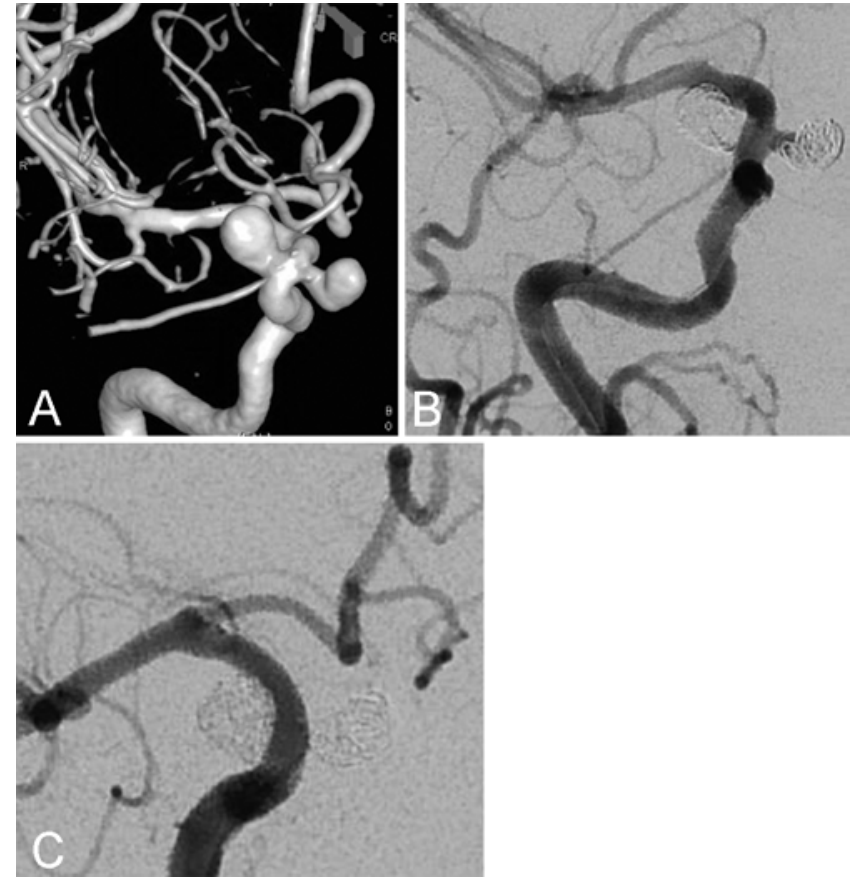

FIG. 3. A: Three-dimensional angiographic reconstruction demonstrating a superior hypophyseal artery aneurysm and an ophthalmic artery aneurysm. B: Postembolization injection after deployment of a single PED and concurrent embolization with a partially dense coil mass. Note residual contrast filling of the neck of the superior hypophyseal artery aneurysm. C: Follow-up angiogram obtained 12 months after the procedure, demonstrating complete occlusion of the aneurysms, without in-stent stenosis. Complete endovascular reconstruction of the ICA is achieved.

$\mathrm{mm}$, range 5-14 $\mathrm{mm}$ ) and in 1 patient retreatment was performed after failure of previous (non-PED) stent-assisted coiling.

All PED deployments were successful. The "jailing" technique of a microcatheter in the aneurysmal sac used for coil deployment did not create any complications or technical difficulties in subsequent PED deployment.

In accordance with our goal of achieving only a partially dense coil mass, there were 23 aneurysms (82.1\%) in which either Raymond Grade 2 or 3 occlusion was achieved. In 5 patients (17.9\%) Raymond Grade 1 aneurysmal occlusion was achieved. There were 2 patients in whom we delivered a very small number of coils to achieve our primary goal of creating a partially dense coil mass within the aneurysmal sac. This was our strategy because of instability of the "jailed" microcatheter in the aneurysm, which had a shallow aneurysmal dome associated with a wide neck (Fig. 2).

Clinically, all patients were stable in the immediate postprocedural period without any new neurological deficits. There were no hemorrhagic, thromboembolic, or ischemic complications, and none were due to local mass effect.

\section{Follow-Up Results}

Twenty-three patients (85.2\%) with 24 aneurysms underwent angiographic follow-up (3 have yet to reach any imaging milestones). All of these patients (100\%) demon-
TABLE 1. Patient's demographics and aneurysm characteristics

\begin{tabular}{lc}
\hline \multicolumn{1}{c}{ Variable } & Value \\
\hline Mean age in yrs (range) & $51.8(31-78)$ \\
\hline Male/female & $1: 26$ \\
\hline Aneurysm location & 1 \\
\hline Cavernous segment & 7 \\
\hline Paraophthalmic segment & 9 \\
\hline OphA & 3 \\
\hline Superior hypophyseal artery & 3 \\
\hline PCoA & 2 \\
\hline AChA & 1 \\
\hline ICA bifurcation & 2 \\
\hline Vertebral artery & 11.9 \\
\hline Mean sac size in mm & 5.4 \\
\hline Mean neck size in mm & 1.48 \\
\hline Mean no. of PEDs per patient & 1.33 \\
\hline Mean no. of PEDs across aneurysmal neck & \\
\hline AChA = anterior choroidal artery; OphA = ophthalmic artery; PCoA = posterior \\
communicating artery.
\end{tabular}

strated complete occlusion on follow-up imaging. Twentytwo patients with 23 aneurysms $(91.7 \%$ of the patients who reached their MRA follow-up milestone) who underwent short-term (mean 3.4 months, median 3 months, range 3-5 months) MRI/MRA follow-up demonstrated complete occlusion of the aneurysm (Fig. 1). There were no radiographic signs of ischemia. Fourteen patients with 15 aneurysms $(87.5 \%$ of the patients who reached their formal angiographic follow-up milestone) underwent midterm follow-up angiography (mean 9.4 months, median 9.5 months, range 5-13 months). All of these patients demonstrated complete aneurysmal occlusion. We did not notice or measure any in-stent stenosis on follow-up digital subtraction angiography in any of the patients in our cohort.

All patients maintained their baseline clinical status during the follow-up period (mean 10.3 months, median 11 months, range 1-25 months) without any new neurological deficits and maintained an mRS score of 0 . No new neuroophthalmological deficits were observed.

\section{Discussion}

The use of PEDs has become a common treatment option for intracranial aneurysms. ${ }^{1,2,4,5,9,21,29,31}$ The use of PEDs has been typically described as a sole endovascular treatment paradigm to treat large, wide-neck aneurysms in the proximal supraclinoid ICA., ${ }^{1,5,21}$ The techniques and indications for PED usage continue to evolve. Recently, the utility of PEDs was described in more distal vascular locations, such as the middle cerebral artery and anterior cerebral artery and in the posterior circulation territories. ${ }^{21,27,29,31}$ We report the safe and efficacious utility of PED deployment with concurrent simultaneous partially dense coiling of the aneurysmal sac for treatment of various intracranial aneurysms.

Based on our results, we believe that total packing of the aneurysmal sac in the setting of immediate placement 
TABLE 2. Patients, aneurysmal and follow-up characteristics

\begin{tabular}{|c|c|c|c|c|c|c|c|c|c|}
\hline $\begin{array}{l}\text { Case } \\
\text { No. }\end{array}$ & $\begin{array}{l}\text { Age } \\
\text { (yrs) }\end{array}$ & Aneurysm Location & $\begin{array}{c}\text { Maximal Sac } \\
\text { Size }(\mathrm{mm})\end{array}$ & $\begin{array}{l}\text { Neck Size } \\
(\mathrm{mm})\end{array}$ & No. of PEDs & $\begin{array}{l}\text { No. of PEDs } \\
\text { Across Neck }\end{array}$ & $\begin{array}{l}\text { Raymond } \\
\text { Score* }^{*}\end{array}$ & $\begin{array}{c}\text { Time to MRA } \\
\text { (mos) }\end{array}$ & $\begin{array}{c}\text { Time to DSA } \\
\text { (mos) }\end{array}$ \\
\hline 1 & 51 & Paraophthalmic segment & 12 & 7 & 1 & 1 & 3 & 3 & 9 \\
\hline 2 & 74 & Superior hypophyseal artery & 10.5 & 6 & 1 & 1 & 3 & 4 & 10 \\
\hline 3 & 62 & OphA & 10.7 & 5.5 & 2 & 2 & 3 & 3 & 12 \\
\hline 4 & 46 & OphA & 11 & 6.5 & 1 & 1 & 3 & 3 & 13 \\
\hline 5 & 47 & PCoA & 19 & 5 & 2 & 2 & 3 & 4 & 12 \\
\hline 6 & 50 & Paraophthalmic segment & 19 & 6 & 2 & 2 & 3 & 3 & 12 \\
\hline 7 & 49 & Paraophthalmic segment & 8.5 & 4.5 & 1 & 1 & 3 & 3 & 11 \\
\hline 8 & 62 & PCoA & 12 & 6 & 1 & 1 & 3 & NA & 9 \\
\hline 9 & 55 & Superior hypophyseal artery; OphA & $7.5 ; 7.5$ & $4 ; 3$ & 1 & 1 & $3 ; 3$ & 3 & 13 \\
\hline 10 & 63 & Intradural vertebral artery & 31 & 11 & 3 & 3 & 3 & NA & NA \\
\hline 11 & 52 & OphA & 20 & 7 & 2 & 2 & 1 & 3 & 7 \\
\hline 12 & 47 & OphA & 6.5 & 3 & 1 & 1 & 1 & 3 & NA \\
\hline 13 & 41 & Paraophthalmic segment & 4.2 & 3 & 1 & 1 & 3 & 3 & 7 \\
\hline 14 & 72 & AChA & 7 & 3.5 & 1 & 1 & 2 & 4 & 5 \\
\hline 15 & 39 & ICA bifurcation & 10 & 5 & 1 & 1 & 1 & 4 & 6 \\
\hline 16 & 46 & Paraophthalmic segment & 9 & 7 & 1 & 1 & 3 & 3 & 5 \\
\hline 17 & 55 & PCoA & 9.8 & 3.1 & 1 & 1 & 2 & 5 & DRM \\
\hline 18 & 55 & OphA & 8 & 3.5 & 1 & 1 & 1 & 4 & DRM \\
\hline 19 & 31 & OphA & 11 & 4 & 2 & 2 & 3 & 3 & DRM \\
\hline 20 & 35 & AChA & 15.1 & 6.5 & 1 & 1 & 2 & 3 & DRM \\
\hline 21 & 58 & Intradural vertebral artery & 15 & 14 & 3 & 2 & 3 & 4 & DRM \\
\hline 22 & 32 & Paraophthalmic segment & 7 & 4 & 1 & 1 & 3 & 3 & DRM \\
\hline 23 & 50 & Paraophthalmic segment & 9 & 4.5 & 3 & 1 & 3 & 4 & DRM \\
\hline 24 & 78 & OphA & 12 & 4.5 & 1 & 1 & 2 & 3 & DRM \\
\hline 25 & 58 & Cavernous segment & 25 & 5 & 2 & 2 & 3 & DRM & DRM \\
\hline 26 & 58 & OphA & 7 & 3.6 & 2 & 1 & 1 & DRM & DRM \\
\hline 27 & 44 & Superior hypophyseal artery & 8 & 5 & 1 & 1 & 3 & DRM & DRM \\
\hline
\end{tabular}

DRM = did not reach milestone; $D S A=$ digital subtraction angiography; $N A=$ not available .

* Scores immediately postprocedure.

of a PED is not required. Packing density is well recognized as a predicting factor for persistent aneurysm occlusion. ${ }^{20}$ Large and wide-neck aneurysms, however, demonstrate high rates of recanalization despite dense packing even in the setting of standard stent deployment across the neck. ${ }^{3}$ We hypothesize that the low porosity of the PED, compared with standard stents, may allow for a significant reduction of the packing density of the coil mass in the aneurysm with the achievement of complete long-term occlusion.

There are several clear and distinct benefits derived from this approach. Subtotal sac packing reduces the need to coil directly down to and across the aneurysm neck; thus, it reduces the risk of coils protruding into the parent vessel subjacent to the PED. This aspect of the treatment therefore becomes less technically challenging with increased safety, particularly at the level of the aneurysm neck. ${ }^{13,25}$ In our series, all cases demonstrated complete and rapid aneurysm occlusion visualized on early MRA (3-5 months), and $100 \%$ of patients who reached the milestone demonstrated complete aneurysmal occlusion on midterm formal cerebral angiographic follow-up.
Our treatment paradigm is not completely novel. The use of PEDs and coils has been previously described (Table 3)., $, 6,8,10,14-16,18,21,24,26$ The rate of this treatment paradigm in series that describe the use of PEDs is variable (0.9\%-51.6\%); however, no homogeneous larger series using the exclusive combination of PEDs and coils has been described. The various series cited in the literature did describe cases of combined treatment; however, only 1 series described the combined technique in multiple cases ( 9 cases, $47 \%$ of that series) and then further provided the occlusion rates of this subgroup as well as associated complications. The use of PEDs with the addition of coils has been described by Siddiqui et al. ${ }^{24}$ for the treatment of a giant MCA aneurysm. Their patient, who was treated with 2 PEDs and a dense coil mass, experienced acute postprocedural thrombosis of the PED. The authors suggested that this likely occurred due to the mass effect and thrombogenicity of the dense coil mass. Based on these findings the authors proposed the placement of a less dense coil mass in addition to PEDs for the treatment of large or giant distal intracranial aneurysms. ${ }^{24}$ Despite utilizing coils in the aneurysm sac, we did not observe any early or 
TABLE 3. Summary of previous descriptions of concurrent use of PEDs and coils in the literature: incidence, occlusion rates, and complications in heterogeneous series

\begin{tabular}{|c|c|c|c|}
\hline \multirow{2}{*}{$\begin{array}{c}\text { Authors \& } \\
\text { Year }\end{array}$} & \multirow{2}{*}{$\begin{array}{c}\text { No. of PEDs \& Coils/ } \\
\text { Overall Cases }\end{array}$} & \multicolumn{2}{|c|}{ PEDs \& Coils } \\
\hline & & Occlusion & Complications \\
\hline $\begin{array}{l}\text { Lylyk et al., } \\
2009\end{array}$ & $4 / 63(6 \%)$ & NP & NP \\
\hline $\begin{array}{l}\text { Szikora et al., } \\
2010\end{array}$ & $9 / 19(47 \%)$ & $9 / 9(100 \%)$ & $\begin{array}{l}1 \text { retinal branch oc- } \\
\text { clusion (visual } \\
\text { field defect) }\end{array}$ \\
\hline $\begin{array}{l}\text { Nelson et al., } \\
2011\end{array}$ & $16 / 31(51.6 \%)$ & NP & NP \\
\hline $\begin{array}{l}\text { Fischer et al., } \\
2012\end{array}$ & $3 / 101(3 \%)$ & NP & 1 massive IVH \\
\hline $\begin{array}{l}\text { McAuliffe et } \\
\text { al., } 2012\end{array}$ & $6 / 57(10.5 \%)$ & NP & $\begin{array}{l}1 \text { retinal branch oc- } \\
\text { clusion (no clini- } \\
\text { cal sequelae) }\end{array}$ \\
\hline $\begin{array}{l}\text { Saatci et al., } \\
2012\end{array}$ & $11 / 251(4 \%)$ & $\mathrm{NP}$ & NP \\
\hline $\begin{array}{l}\text { Chitale et al., } \\
2012\end{array}$ & $1 / 36(3 \%)$ & $\mathrm{NP}$ & $\mathrm{NP}$ \\
\hline $\begin{array}{l}\text { Siddiqui et } \\
\text { al., } 2012\end{array}$ & Case report & - & $\begin{array}{l}\text { Acute PED throm- } \\
\text { bosis }\end{array}$ \\
\hline $\begin{array}{l}\text { Becske et al., } \\
2013\end{array}$ & $1 / 106(0.9 \%)$ & NP & NP \\
\hline $\begin{array}{r}\text { Dornbos et } \\
\text { al., } 2013\end{array}$ & Case report & Complete & No \\
\hline $\begin{array}{l}\text { Nossek et al., } \\
2014\end{array}$ & Case report & Complete & No \\
\hline
\end{tabular}

IVH = intraventricular hemorrhage; NP = not provided; $-=$ not applicable.

delayed mass effect in our cohort (including 2 giant aneurysms and 3 aneurysms larger than $15 \mathrm{~mm}$ ), inclusive of any signs of optic pathway compression. In our experience, subtotal packing with concurrent PED deployment may allow for early thrombosis and future size reduction of the aneurysm sac.

According to most series in the literature, there has been a need to use multiple PEDs to achieve significant flow diversion and flow reduction in an aneurysm sac, especially when large and giant aneurysms are treated. ${ }^{1,21}$ With treatment using multiple PEDs, the rate of incomplete occlusion during the follow-up period has been as high as $5.6 \%-13.2 \%, 1,21$ and the rate of retreatment has been noted to be $3.2 \%-7.9 \% .{ }^{10,14-16,21,26}$ The rate of complete occlusion of aneurysms treated with PEDs as a sole endovascular device at 6-month follow-up ranges between $52 \%$ and $94.4 \% .^{10,14-16,21,26}$ With our treatment paradigm, utilizing a mean of 1.33 PEDs per aneurysm concurrently with subtotal coiling, we noted a high and early complete occlusion rate.

We attempted to deploy the least number of PEDs in each case to reduce the amount of intimal coverage in the parent vessel. This paradigm addresses possible complications of deployment of multiple PEDs, such as malalignment of multiple PEDs, early stent thrombosis, and future in-stent stenosis. The deployment of multiple PEDs can be challenging in respect to accurate stent landing zones and verification of perfect alignment in the presence of tortuous vascular anatomy and acute curves in the parent vessel. The PED size used is determined by the vessel diameter at the level of the neck and at the desired level of the proximal landing zone. The goal is to achieve maximal metallic coverage and the lowest porosity to maximize flow diversion..$^{22}$ In certain cases an additional PED is required to match diameter discrepancies in the proximal landing zone.

The use of a single PED is clearly beneficial for the treatment of aneurysms in the vicinity of perforators. Our treatment paradigm enabled us to use a single PED across critical end-arteries such as the anterior choroidal artery and the medial lenticulostriate arteries (Fig. 4) ${ }^{18}$ The ability to effectively use a single PED increases the safety of treatment and reduces potential ischemic events in the setting of early and complete aneurysm occlusion. Additionally, when reviewing our entire cohort, the use of fewer PEDs allowed us to shorten the duration of dual antiplatelet therapy.

Hemorrhagic complications after PED deployment have been previously described at an incidence of $1.6 \%-5.6 \%$ in several retrospective reviews. ${ }^{10,14-16,21,26}$ In our cohort, with utilization of our treatment paradigm, we did not experience any similar morbidity or mortality, such as hemorrhagic complications or delayed aneurysmal rupture. Critical changes in intraaneurysmal flow and pressure may be the basis of these positive results.

When using PEDs alone as a treatment modality, large and giant aneurysms may need a longer time to completely occlude. ${ }^{21}$ Thus, these aneurysms are still at risk for rupture in the follow-up period prior to total occlusion. Several recently published computational and in vitro fluid dynamic models have quantitated intraaneurysmal pressure changes. PEDs have been reported to induce reductions in intraaneurysmal pressures of only $2-10 \mathrm{~mm} \mathrm{Hg}$ despite the flow velocity changes. ${ }^{11,12,23}$ The authors concluded that in a nonthrombosed aneurysm or in an aneurysm with delayed thrombosis, the intraaneurysmal pressure remains essentially unchanged regardless of the amount of the intraaneurysmal flow velocity reduction induced by the PED. ${ }^{23}$ Established long-term experience with aneurysms occluded by coils demonstrates prevention of hemorrhage after dense packing of the aneurysm. This may be suggestive of changes in the intraaneurysmal flow velocities and pressures. With our technique of subtotal coiling with concurrent placement of PEDs, we have combined the effects of the 2 modalities, presumably modifying the flow dynamics and pressure profiles within the aneurysm sac. This is correlated with excellent short-term complete occlusion rates without any incidence of delayed ruptures.

\section{Study Limitations}

Our study comprises 27 patients harboring 28 aneurysms. This is a relatively small series, and our maximal clinical and radiographic follow-up is midterm. Thus, our results need to be further substantiated by ongoing data collection analysis and larger numbers of patients. Our technique may be problematic in respect to the evaluation of wall apposition immediately post-PED deployment in the angiography suite using DynaCT angiography, as the 


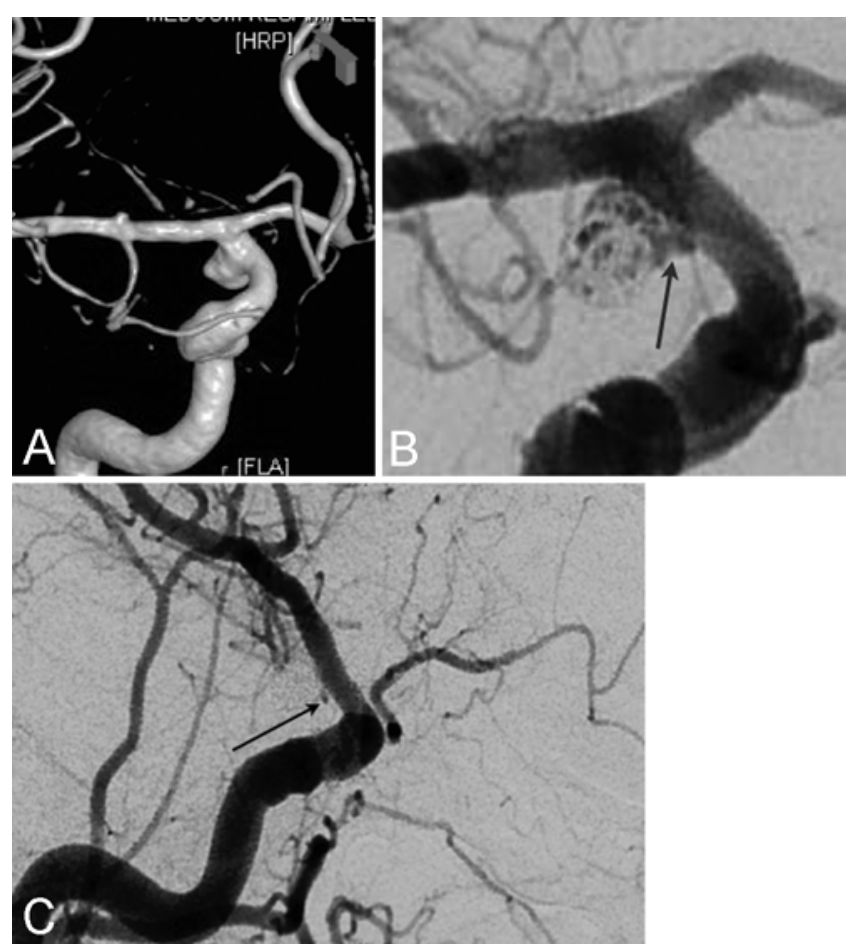

FIG. 4. A: Three-dimensional angiographic reconstruction of an anterior choroidal artery wide-neck aneurysm. B: Postembolization injection after deployment of a single PED and concurrent embolization with a partially dense coil mass. Note residual contrast filling of the neck at the origin of the anterior choroidal artery (arrow). C: Follow-up angiogram obtained 6 months after the procedure, demonstrating complete aneurysm occlusion, with patency of the anterior choroidal artery (arrow).

coil mass induces an obscuring artifact at the level of the PED.

\section{Conclusions}

We found that the deployment of a minimal number of PEDs with the concurrent use of subtotal aneurysm packing with coils achieved early aneurysm occlusion rates with favorable midterm clinical and angiographic outcomes. There were no intraprocedural complications. The use of concurrent coiling to achieve a partially dense coil mass may assist in reducing the number of PEDs deployed, thus allowing for safer treatments and earlier time intervals to complete occlusion. The technique proposed has the potential to reduce the rate of hemorrhagic complications due to delayed aneurysmal rupture and thromboembolic events. Early complete occlusion and less intimal coverage in the parent vessel may shorten the need for prolonged dual antiplatelet therapy.

\section{Acknowledgment}

The authors thank Mr. Robert Ferrara for his professional support and advice.

\section{References}

1. Becske T, Kallmes DF, Saatci I, McDougall CG, Szikora I, Lanzino G, et al: Pipeline for uncoilable or failed aneurysms: results from a multicenter clinical trial. Radiology 267:858868,2013

2. Briganti F, Napoli M, Tortora F, Solari D, Bergui M, Boccardi E, et al: Italian multicenter experience with flow-diverter devices for intracranial unruptured aneurysm treatment with periprocedural complications-a retrospective data analysis. Neuroradiology 54:1145-1152, 2012

3. Chalouhi N, Jabbour P, Singhal S, Drueding R, Starke RM, Dalyai RT, et al: Stent-assisted coiling of intracranial aneurysms: predictors of complications, recanalization, and outcome in 508 cases. Stroke 44:1348-1353, 2013

4. Chalouhi N, Starke RM, Yang S, Bovenzi CD, Tjoumakaris $\mathrm{S}$, Hasan D, et al: Extending the indications of flow diversion to small, unruptured, saccular aneurysms of the anterior circulation. Stroke 45:54-58, 2014

5. Chalouhi N, Tjoumakaris S, Starke RM, Gonzalez LF, Randazzo C, Hasan D, et al: Comparison of flow diversion and coiling in large unruptured intracranial saccular aneurysms. Stroke 44:2150-2154, 2013

6. Chitale R, Gonzalez LF, Randazzo C, Dumont AS, Tjoumakaris S, Rosenwasser R, et al: Single center experience with Pipeline stent: feasibility, technique, and complications. Neurosurgery 71:679-691, 2012

7. Cho WS, Kim SS, Lee SJ, Kim SH: The effectiveness of $3 \mathrm{~T}$ time-of-flight magnetic resonance angiography for follow-up evaluations after the stent-assisted coil embolization of cerebral aneurysms. Acta Radiol 55:604-613, 2014

8. Dornbos D III, Pillai P, Sauvageau E: Flow diverter assisted coil embolization of a very small ruptured ophthalmic artery aneurysm. J Neurointerv Surg [epub ahead of print], 2013

9. Fiorella D, Woo HH, Albuquerque FC, Nelson PK: Definitive reconstruction of circumferential, fusiform intracranial aneurysms with the Pipeline embolization device. Neurosurgery 62:1115-1121, 2008

10. Fischer S, Vajda Z, Aguilar Perez M, Schmid E, Hopf N, Bäzner H, et al: Pipeline embolization device (PED) for neurovascular reconstruction: initial experience in the treatment of 101 intracranial aneurysms and dissections. Neuroradiology 54:369-382, 2012

11. Kerl HU, Boll H, Fiebig T, Figueiredo G, Förster A, Nölte IS, et al: Implantation of Pipeline flow-diverting stents reduces aneurysm inflow without relevantly affecting static intraaneurysmal pressure. Neurosurgery 74:321-334, 2014

12. Larrabide I, Aguilar ML, Morales HG, Geers AJ, Kulcsár $Z$, Rüfenacht D, et al: Intra-aneurysmal pressure and flow changes induced by flow diverters: relation to aneurysm size and shape. AJNR Am J Neuroradiol 34:816-822, 2013

13. Lessne ML, Shah P, Alexander MJ, Barnhart HX, Powers CJ, Golshani K, et al: Thromboembolic complications after Neuroform stent-assisted treatment of cerebral aneurysms: the Duke Cerebrovascular Center experience in 235 patients with 274 stents. Neurosurgery 69:369-375, 2011

14. Lylyk P, Miranda C, Ceratto R, Ferrario A, Scrivano E, Luna HR, et al: Curative endovascular reconstruction of cerebral aneurysms with the Pipeline embolization device: the Buenos Aires experience. Neurosurgery 64:632-643, 2009

15. McAuliffe W, Wycoco V, Rice H, Phatouros C, Singh TJ, Wenderoth J: Immediate and midterm results following treatment of unruptured intracranial aneurysms with the Pipeline Embolization Device. AJNR Am J Neuroradiol 33:164170, 2012

16. Nelson PK, Lylyk P, Szikora I, Wetzel SG, Wanke I, Fiorella D: The Pipeline Embolization Device for the intracranial treatment of aneurysms trial. AJNR Am J Neuroradiol 32:34-40, 2011

17. Nossek E, Chalif DJ, Chakraborty S, Setton A: Modifying flow in the ICA bifurcation: Pipeline deployment from the supraclinoid ICA extending into the M1 segment-clinical and anatomic results. AJNR Am J Neuroradiol 35:2125-2129, 2014 
18. Nossek E, Chalif DJ, Levine M, Setton A: Modifying flow in the ACA-ACoA complex: endovascular treatment option for wide-neck internal carotid artery bifurcation aneurysms. J Neurointerv Surg [epub ahead of print], 2014

19. O'Kelly CJ, Krings T, Fiorella D, Marotta TR: A novel grading scale for the angiographic assessment of intracranial aneurysms treated using flow diverting stents. Interv Neuroradiol 16:133-137, 2010

20. Raymond J, Guilbert F, Weill A, Georganos SA, Juravsky L, Lambert A, et al: Long-term angiographic recurrences after selective endovascular treatment of aneurysms with detachable coils. Stroke 34:1398-1403, 2003

21. Saatci I, Yavuz K, Ozer C, Geyik S, Cekirge HS: Treatment of intracranial aneurysms using the Pipeline flow-diverter embolization device: a single-center experience with longterm follow-up results. AJNR Am J Neuroradiol 33:14361446,2012

22. Shapiro M, Raz E, Becske T, Nelson PK: Variable porosity of the Pipeline Embolization Device in straight and curved vessels: a guide for optimal deployment strategy. AJNR Am J Neuroradiol 35:727-733, 2014

23. Shobayashi Y, Tateshima S, Kakizaki R, Sudo R, Tanishita $\mathrm{K}$, Viñuela F: Intra-aneurysmal hemodynamic alterations by a self-expandable intracranial stent and flow diversion stent: high intra-aneurysmal pressure remains regardless of flow velocity reduction. J Neurointerv Surg 5 Suppl 3:iii38iii42, 2013

24. Siddiqui AH, Kan P, Abla AA, Hopkins LN, Levy EI: Complications after treatment with Pipeline embolization for giant distal intracranial aneurysms with or without coil embolization. Neurosurgery 71:E509-E513, 2012

25. Spiotta AM, Wheeler AM, Smithason S, Hui F, Moskowitz S: Comparison of techniques for stent assisted coil embolization of aneurysms. J Neurointerv Surg 4:339-344, 2012

26. Szikora I, Berentei Z, Kulcsar Z, Marosfoi M, Vajda ZS, Lee $\mathrm{W}$, et al: Treatment of intracranial aneurysms by functional reconstruction of the parent artery: the Budapest experience with the Pipeline Embolization Device. AJNR Am J Neuroradiol 31:1139-1147, 2010
27. Wajnberg E, Silva TS, Johnson AK, Lopes DK: Progressive deconstruction: a novel aneurysm treatment using the Pipeline embolization device for competitive flow diversion: case report. Neurosurgery 10 (Suppl 1):E161-E166, 2014

28. Wong JH, Mitha AP, Willson M, Hudon ME, Sevick RJ, Frayne R: Assessment of brain aneurysms by using high-resolution magnetic resonance angiography after endovascular coil delivery. J Neurosurg 107:283-289, 2007

29. Yavuz K, Geyik S, Saatci I, Cekirge HS: Endovascular treatment of middle cerebral artery aneurysms with flow modification with the use of the Pipeline Embolization Device. AJNR Am J Neuroradiol 35:529-535, 2014

30. Yoneoka Y, Watanabe M, Nishino K, Ito Y, Kwee IL, Nakada $\mathrm{T}$, et al: Evaluation of post-procedure changes in aneurysmal lumen following detachable coil-placement using multiplanar reconstruction of high-field (3.0T) magnetic resonance angiography. Acta Neurochir (Wien) 150:351-358, 2008

31. Zanaty M, Chalouhi N, Tjoumakaris SI, Gonzalez LF, Rosenwasser R, Jabbour P: Flow diversion for complex middle cerebral artery aneurysms. Neuroradiology 56:381-387, 2014

\section{Author Contributions}

Conception and design: Setton, Nossek. Acquisition of data: Setton, Nossek, Chakraborty, Lombardo, Black. Analysis and interpretation of data: all authors. Drafting the article: all authors. Critically revising the article: Setton, Nossek, Chalif, Black. Reviewed submitted version of manuscript: Setton, Nossek, Chalif. Approved the final version of the manuscript on behalf of all authors: Setton. Statistical analysis: Nossek. Administrative/ technical/material support: Nossek, Lombardo. Study supervision: Setton.

\section{Correspondence}

Avi Setton, Department of Neurosurgery, North Shore-Long Island Jewish Health System, North Shore University Hospital, 300 Community Dr., 9 Tower, Manhasset, NY 11030. email: asetton@nshs.edu. 